\title{
Variações intra e intermetropolitanas da desigualdade de renda racial
}

\author{
Intra- and inter-metropolitan variations \\ of racial income inequality
}

Leonardo Souza Silveira

Jerônimo Oliveira Muniz

\section{Resumo}

Qual é o diferencial de renda entre brancos e negros dentro de uma mesma região metropolitana? Qual situação coloca o indivíduo em maior desvantagem: a cor da pele ou o local de residência? Políticas de mitigação de desigualdades devem ser universais ou locais? Para responder esses questionamentos comparamos os salários de brancos e negros no centro e na periferia de seis regiões metropolitanas utilizando diferentes recortes geográficos. Os resultados obtidos a partir da PNAD (2008) demonstram que a cor da pele tem maior impacto no salário predito dos indivíduos do que a localização dentro da cidade e indicam substancial heterogeneidade espacial nos diferenciais raciais de rendimento.

Palavras-chave: segregação; metrópoles; raça; desigualdade; renda.

\begin{abstract}
What is the income gap between blacks and whites within the same metropolitan region? What variable puts individuals in greatest disadvantage: skin color or place of residence? Should mitigating policies against inequality be global or local? To answer these questions we compare the wages of blacks and whites living in the center and in the periphery of six Brazilian metropolitan regions. Results from the PNAD (2008) show that the impact of skin color on wages is larger than that of the geographic location within the city. We also show that there is substantial spatial heterogeneity in income differentials by race.
\end{abstract}

Keywords: segregation; metropolis; race; inequality; income. 


\section{Introdução}

Desigualdade e segregação raciais são temas que dialogam entre si. Os diferenciais raciais de renda e de acesso a ocupações de maior prestígio segmentam o mercado de trabalho a partir de características adquiridas ao longo do ciclo de vida - tais como escolaridade, experiência, idade (Becker, 1962), valores morais e redes de influência, vulgarmente denominadas capital social (Bourdieu, 1986), e também características atribuídas por terceiros - tais como a raça, gênero, beleza, saúde, inteligência, riqueza, origem e etnia (Piore, 2008). Esses atributos individuais, por serem socialmente percebidos, dependem das reações de ambientes específicas a essas características para exercerem seus efeitos diretos e indiretos e definir como ocorrerá o acesso de determinados grupos às posições no mercado de trabalho e à respectiva geração de renda. Características atribuídas são, portanto, sensíveis à resposta do ambiente no qual se encontram. A localização residencial desses grupos e a forma como se agrupam e se distribuem no espaço servem então como uma variável indutora e reprodutora de desigualdades. A segmentação influencia não só o acesso a serviços públicos, ao capital social e às oportunidades de escolarização e emprego, mas também afeta a atribuição de características sociais (como raça ou cor da pele) vinculadas ao tamanho e dinâmica das desigualdades.

Neste artigo, exploramos a associação entre segregação residencial e desigualdade racial, cientes de que a raça de cada indivíduo não causa nenhum tipo de diferença, mas está atrelada a mecanismos causadores dos diferenciais entre brancos e negros. Os negros, por exemplo, concentram-se em zonas de pobreza intrinsicamente favoráveis à reprodução de desigualdades. A detecção da concentração e variabilidade espaciais da desigualdade racial, entretanto, não a torna menos penosa para aqueles que a sofrem, mas contribui para a mensuração mais precisa dos mecanismos envolvidos. Sistematizamos o uso da variável núcleo/periferia de maneira gradual e fragmentada, trabalhando com subamostras diferentes para os modelos estatísticos utilizados, por região metropolitana e por grupos raciais (brancos e negros). A intenção é ilustrar a variabilidade das desigualdades raciais entre o núcleo e a periferia, já que é esta dicotomização que fragmenta um espaço tão heterogêneo como as regiões metropolitanas brasileiras.

Investigamos, portanto, a associação entre a localização intrametropolitana e os diferenciais de rendimentos entre brancos e negros, atentando-nos à especificidade contextual de cada região metropolitana. As seguintes perguntas, em particular, norteiam esta pesquisa: a segregação residencial aumenta ou ameniza as desigualdades? Quão díspares são os diferenciais raciais de rendimento entre as regiões metropolitanas? Sabemos que, em média, brancos ganham mais que negros mesmo depois de controlarmos por heterogeneidades observáveis e atributos produtivos, mas quais o tamanho e a variabilidade desse diferencial quando comparamos áreas metropolitanas do Brasil? Os diferenciais raciais são, em geral, mais homogêneos nas periferias que nos núcleos metropolitanos?

Os resultados mostram a variabilidade da desigualdade racial tanto do ponto de vista intra - núcleo e periferia - quanto intermetropolitano, além de mostrarem onde e quanto as 
segmentações raciais e espaciais estão atreladas à variabilidade do diferencial de rendimentos entre brancos e não brancos.

0 artigo está dividido em quatro partes, além dessa introdução e uma conclusão. Na primeira, são abordados os estudos acerca das desigualdades raciais no Brasil e estudos que evidenciam os impactos de se viver em diferentes locais das grandes metrópoles: há diferenças nas oportunidades de vida, emprego, participação, escolaridade, entre outros, para quem vive em regiões mais ou menos centrais das metrópoles brasileiras? Com isso buscamos afinidades entre esses dois escopos teóricos, compreendendo-os como diferentes dimensões de desigualdades sociais. Na segunda parte, apresentamos os três modelos estatísticos utilizados. Por meio desses, fazemos uma análise didático-comparativa sobre como a escolha de modelos de regressão podem vir a afetar a mensuração das desigualdades entre grupos raciais intra e intermetropolitanos. A terceira parte discute os resultados obtidos e tece considerações sobre as incertezas geográficas e metodológicas envolvidas na mensuração de desigualdades raciais. A quarta parte, por fim, aponta as contribuições do artigo para a área de estudo sobre desigualdade racial, considerando a segmentação e a segregação residenciais.

\section{Desigualdade racial e segregação residencial no Brasil}

Autores anteriores à década de 1950 viam no Brasil uma sociedade racialmente harmônica e com desigualdades temporais decorrentes do período escravocrata (Freyre, 1987 [1933]; Pierson, 1945). A clamada democracia racial, entretanto, não persiste além do direto ao sufrágio. Estudos posteriores à década de 1950 demonstram a existência de relações raciais marcadas pela hierarquia entre brancos e negros na sociedade brasileira (Fernandes, 2008 [1969]; Hasenbalg, 2005 [1979]; Hasenbalg et al., 1999) e a sua persistência ao longo do tempo (Soares, 2008a, 2008b; Osório, 2009). De fato, as disparidades raciais são reconhecidas como componentes da dinâmica social brasileira, tendo em vista o atual debate acerca de políticas afirmativas raciais que se justificam pela redução dessas desigualdades. Estudos sobre diferenciais de rendimento, mobilidade intergeracional e inserção no mercado de trabalho abordam constantemente a desvantagem dos negros em comparação aos brancos (Soares, 2000; Costa Ribeiro, 2006; Henriques, 2001; Hansenbalg, 2005), sobretudo entre as classes socioeconomicamente superiores (Bailey et al., 2013; Costa Ribeiro, 2006). Esses estudos apontam como pretos e pardos se encontram em condições desfavoráveis em relação aos brancos, seja pela desigualdade de acesso, de recompensas ou de oportunidades, mensuradas, por exemplo, por níveis de escolaridade, salários ou inserção em posições de classe (Soares, 2000; Santos, 2009).

Uma das tradições dos estudos de estratificação social consiste em se "medir a discriminação" segundo marcadores sociais como raça, sexo e etnia. Para isso, a praxe dominante tem sido observar pessoas com as mesmas características produtivas (escolaridade, posição no mercado de trabalho, idade, experiência), que supostamente justificariam seus salários, e em 
seguida assumir que as diferenças remanescentes, não associadas a esses atributos, seriam oriundas de práticas discriminatórias. Esses estudos compreendem que essas "características atribuídas" (Piore, 2008) seriam determinantes na definição salarial dos indivíduos, já que as mulheres não teriam suas qualificações reconhecidas da mesma forma que o homem, nem o negro em comparação ao brancos, ou o imigrante com relação ao nativo.

Soares (2000), por exemplo, mostra que homens negros ganhavam, em 1998, $R \$ 389,76$ a menos que os brancos. Desse diferencial, $8,6 \%$ deve-se ao fato de os negros estarem ocupados em setores ou terem vínculos inferiores aos dos brancos, e o restante deve-se a outras características e processos não observáveis, entre os quais se inclui a habilidade de mobilização de capital social, a discriminação e desvantagens acumuladas ao longo do ciclo de vida (Hasenbalg e Silva, 2003). Coincidentemente, ou não, esses pretos e pardos em desvantagem estariam concentrados em Estados mais pobres e fora de regiões metropolitanas.

É preciso estar atento às diferenças regionais quando se deseja mensurar experiências discriminatórias já que diferenças na composição racial dessas populações

[...] seguramente influenciam as formas de sociabilidade manifestadas em cada uma delas, não apenas do ponto de vista racial, mas também na perspectiva de outras dimensões de desigualdade e tratamento interpessoal, como classe, gênero e idade, entre outras. (Bastos e Faerstein, 2012, p. 89)

Campante et al. (2004), por exemplo, constataram que o componente discriminatório do diferencial de salários no Sudeste é quase duas vezes e meia maior que no Nordeste, e tem um caráter "elitista" da discriminação, já que essa aumenta de acordo com os centis de renda. Cavalieri e Fernandes (1998) também encontraram variações nos diferenciais de rendimento por raça e gênero em diversas regiões metropolitanas do Brasil, demonstrando a relevância de estudos comparativos que considerem as especificidades de cada região. Eles encontraram variações entre os diferenciais de rendimentos entre brancos e não brancos de nove regiões metropolitanas do Brasil, onde o diferencial na região metropolitana de São Paulo foi o menor, com brancos recebendo $9,85 \%$ a mais que não brancos, ao passo que na região metropolitana de Salvador esse valor é de 53,34\%. As desigualdades, portanto, variam de forma regional e situacional, incorporando características socioeconômicas, culturais e estruturais em cada uma delas (Wilson, 2009).

A análise intermetropolitana se justifica pela especificidade das metrópoles, nas quais encontramos cenários sócio-ocupacionais marcados por dinâmicas distintas. Nos anos 1980, por exemplo, houve aumento substancial da pobreza nas regiões metropolitanas do Nordeste, aumento médio em Belo Horizonte e no Rio de Janeiro, e menor em São Paulo e nas metrópoles do Sul (Lima, 1999). Ou seja, as estruturas econômicas e sociais diferem no espaço, assim com as desigualdades.

A literatura acerca da segregação nas metrópoles brasileiras é marcada fundamentalmente por trabalhos publicados a partir da década de 1970 (Maricato, 1977; Bonduki e Rolnik, 1982), que desencadearam reflexões sobre a configuração dos espaços metropolitanos no país. Esses seguiam uma abordagem 
marxista que apresentava as cidades como espaços segregados com forte influência do mercado imobiliário, separadas pelas categorias analíticas de "centro" e "periferia", sendo a primeira marcada pela presença de grupos sociais mais abastados, melhores serviços públicos e oportunidades de emprego, ao passo que as periferias teriam características opostas, marcadas pela violência, pobreza, precariedade das oportunidades econômicas e urbanísticas, e como forma de acesso à moradia pelos mais pobres, apesar de estudos recentes mostrarem as periferias como locais de maior geração de empregos (Lago, 2007), com oferta de moradias luxuosas para grupos com maior renda (Caldeira, 2003) ou mais presentes nas manifestações culturais (Andrade e Jayme, 2011).

Contudo, ainda que as periferias tenham ganhado mais centralidade (social, econômica, simbólica ou cultural), as metrópoles brasileiras permanecem como centros referenciais compostos por grupos socioeconômicos mais altos e as periferias mais pobres (Marques et al., 2008). Apesar da crescente prevalência e migração de grupos abastados para a periferia, isso não "desconfigura" o padrão centro-periferia predominante nas metrópoles nacionais, nas quais os espaços intrametropolitanos continuam sendo ocupados de maneira desigual, com os municípios centrais ocupados por grupos em posições sociais mais elevadas do que os que vivem nas periferias ${ }^{1}$ (Caldeira, 2003; Ribeiro et al., 2011).

As diferenças intrametropolitanas são consagradas nos estudos sociológicos, principalmente invocando os estudos sobre as inner cities nos Estados Unidos (Wilson, 1987; 2009). Segundo Wilson (2009) existem fatores estruturais e culturais que recaem sob as situações de pobreza dos negros residentes em áreas degradadas da cidade, contribuindo para a sua perpetuação. Os fatores estruturais seriam aqueles relacionados à macroeconomia e às decisões políticas, que impactam diferentemente os grupos sociais, como em situações de aumento de desemprego em que os negros são mais afetados que os brancos. Essas situações se intensificam quando as vagas de emprego se concentram em locais distantes das residências de famílias negras, ou há dificuldade em acessar essas vagas devido à sua baixa escolaridade. Os fatores culturais, como crenças e comportamentos, contrapõem negros e brancos, que se tornam mais rígidos se eles se encontram separados nos espaços metropolitanos. Contudo, esse contexto se distingue do Brasil dada a localização espacial das inner cities nos centros das metrópoles norte-americanas, esvaziados de atividades comerciais e com moradias degradadas, ao passo que no Brasil as periferias são caracterizadas pela sua localização simbólica (relacionada à pobreza e marginalidade), mas também geográfica, nas bordas das regiões metropolitanas.

Nos Estados Unidos, aliás, os estudos de segregação residencial estão em grande maioria relacionados à questão racial. Para Wilson (1987; 2009), a ascensão social de alguns negros e a consequente mudança para bairros de classe média negra, ocasionaram uma situação degradante para aqueles que continuaram nos guetos (ou inner cities). Ainda nos Estados Unidos, é possível encontrar estudos que apontam a dificuldade de negros acessarem 0 mercado de trabalho e as barreiras adicionais quando estes estão em bairros segregados (Kain, 1992; Alba e Logan, 1993; Alba et al., 2000; Patillo, 2005). 
0 mercado imobiliário, em ambos os contextos - brasileiro e norte-americano - tem extrema importância. Porém, há diferenças significativas entre eles. Nos Estados Unidos, ele é retratado como uma barreira entre os grupos raciais, seja culturalmente, através de indisposição entre os grupos, seja por barreiras institucionalizadas, devido à restrição de crédito, por exemplo.

Nas cidades brasileiras, o mercado imobiliário, sob a conivência do poder público, se desenvolveu de maneira que os pobres foram expulsos dos centros em direção às periferias, resultando assim no que chamamos hoje de estrutura centro-periferia (Guimarães, 1991; Caldeira, 2003). Essa "dinâmica metropolitana" não ocorre de maneira igualitária, mas à custa de periferias com pouca infraestrutura urbana, e o baixo custo de seus terrenos se deve às dificuldades encontradas pelos moradores - como a necessidade de utilizar mais de uma viagem de ônibus para se chegar ao trabalho ou a falta de serviços na região.

Segundo a hipótese levantada por Kain (1968), conhecida como spatial mismatch, a distribuição geográfica dos empregos e a segregação residencial (principalmente para o caso norte-americano), funcionam como barreiras para o acesso dos negros ao mercado de trabalho. A localização geográfica seria, portanto, acumulada a outras dificuldades já existentes de ascensão, tais como aquelas em níveis mais altos de escolaridade, posições ocupacionais superiores e melhores salários. Desse modo, a segregação residencial representaria mais do que diferenças de condições de habitação, mas também um empecilho ao acesso e à permanência no mercado de trabaIho (Ihlanfeldt, 1994).
Como afirma Lago (2007), a dicotomia centro-periferia representaria a imagem mais acabada de uma metrópole desigual. Portanto, observamos evidências de que, assim como nos Estados Unidos, também existem nas metrópoles brasileiras mecanismos de reprodução da pobreza dada a concentração de famílias em situações desfavoráveis no mercado de trabaIho. Essa configuração da distribuição espacial da população nas regiões metropolitanas brasileiras é válida devido ao capital social potencialmente homogêneo formado nas periferias e os impactos disso no acesso a informações sobre vagas de empregos (Marques, 2010; Guimarães et al., 2010).

A noção de capital social que utilizamos aqui carrega uma noção territorial. Quer dizer, além da noção teoricamente consolidada por Bourdieu (1986) e Lin (1999), segundo a qual o capital social é um ativo que já se encontra na rede dos indivíduos e varia por classe ou grupo social, outros autores o incorporaram aos diferentes espaços nas metrópoles, dando a ele maleabilidade para variar de acordo com a rede social do local em que o indivíduo está inserido. A partir do estudo de Wilson (1987) e outros que o seguiram abordando o "efeito-vizinhança" (Small e Newman, 2001; Andrade e Silveira, 2011), mostrou-se que a localização geográfica tem relação com a perpetuação das condições socioeconômicas. Estar em locais onde há heterogeneidade social tende a trazer resultados socioeconômicos favoráveis a seus moradores, uma vez que a rede social desses também é heterogênea (Kaztman e Filgueira, 2006; Marques, 2010). ${ }^{2}$

Pressupomos, então, que haja uma situação desfavorável para os moradores de periferias em comparação aos moradores de bairros 
ou municípios mais centrais. Isso, por sua vez, atinge brancos e negros diferentemente, de maneira não aleatória, nem idêntica em todas as regiões metropolitanas. Em São Paulo, por exemplo, há uma concentração sistemática de brancos no centro e negros na periferia (França, 2010). De forma mais ampla, Telles (1992) conclui que as metrópoles brasileiras, em comparação ao padrão norte-americano, têm uma segregação residencial por raça moderada, dado que não houve uma segregação extrema mediada por lei como aconteceu em outros locais do mundo, principalmente nos Estados Unidos ou África do Sul. A segregação racial residencial brasileira não pode ser explicada somente por fatores socioeconômicos, como apontam alguns autores, pois ela ocorre entre grupos raciais do mesmo grupo socioeconômico e aumenta de acordo com as faixas de renda - ou seja, à medida que a renda dos indivíduos aumenta eles tendem a se concentrar em espaços racialmente mais homogêneos (Telles, 1992, 2004).

As desigualdades raciais, portanto, além de variarem segundo o tempo (cf. Soares, 2008) e as formas de classificação racial (Bailey et al., 2013; Muniz, 2010, 2012; Loveman et al., 2011), também variam conforme o espaço em que os grupos sociais ocupam, havendo assim uma permeabilidade entre a estratificação social, racial e espacial.

A nossa proposta consiste em inserir no estudo dos diferenciais raciais de rendimento uma dimensão intrametropolitana e explorar dados que nos aponte o que ocorre nesse nível de análise. Seguindo o apontamento sugerido por Muniz (2010), o objetivo é explorar a variação dos diferenciais de rendimento entre brancos e negros, nas regiões metropolitanas, para mostrar que políticas raciais de inclusão de cunho nacional podem errar 0 alvo ao desconsiderarem as especificidades das desigualdades raciais locais.

0 presente trabalho se orienta pela bibliografia abordada ao comparar a desigualdade racial em diferentes regiões metropolitanas (Cavalieri e Fernandes, 1998; Silva, 1999) e traz novas evidências para esse tipo de estudo tendo em vista as seguintes perguntas: o diferencial de rendimentos entre brancos e negros é semelhante entre as regiões metropolitanas? Qual fator tem maior influência nos diferenciais de rendimentos, cor da pele ou local de moradia? 0 diferencial é o mesmo no núcleo e na periferia das metrópoles brasileiras? E quão sensíveis são as nossas conclusões sobre o tamanho da desigualdade racial em função do nível de agregação utilizado na construção dos nossos modelos estatísticos?

\section{Dados e métodos}

Este trabalho utiliza a PNAD - Pesquisa Nacional por Amostra de Domicílios de 2008 trabalhada pelo Observatório das Metrópoles, que tem o acréscimo das variáveis "núcleo" e "periferia". São compreendidos como "núcleo" os chamados municípios-polo de cada região metropolitana e, como periferia, os demais municípios que as compõem. ${ }^{3} \mathrm{~A}$ amostra da PNAD tem representatividade em nível metropolitano e abrange todo o país.

0 recorte por regiões metropolitanas se deve ao fato de essas serem aglomerados com grande concentração econômica, social, política e cultural que, ao mesmo tempo, resultam 
em profundas desigualdades internas (cf. Ribeiro et al., 2011). A variável núcleo/periferia permite testar se a condição de inserção e remuneração dos indivíduos no mercado de trabalho varia em nível intrametropolitano. Foram selecionadas seis regiões metropolitanas representativas no cenário nacional quanto à composição racial da população: São Paulo, Rio de Janeiro e Porto Alegre, com maioria branca; Belo Horizonte, com $61 \%$ de não bran$\cos _{i}{ }^{4}$ Salvador e Recife, por sua importância no nordeste brasileiro e pela sua composição predominantemente não branca. Desse modo, tem-se uma amostra de regiões diversificadas conforme a localização no cenário nacional e a composição racial.

A Tabela 1 mostra a composição das regiões metropolitanas segundo o número de municípios que se encontram no núcleo e na periferia, e a composição racial predominante nesses dois locais. A composição racial per se não é um indicativo de dinâmicas intrametropolitanas, mas está relacionada à organização política ou de conflitos entre os grupos. Pode indicar, por exemplo, onde houve maior fluxo de escravos ou da imigração europeia
(Hasenbalg, 2005). ${ }^{5}$ Como nos interessa conhecer o diferencial de rendimentos dos indivíduos no mercado de trabalho, utilizamos o "logaritmo natural do salário por hora trabaIhada" como variável dependente. A variável que representa o salário mensal foi dividida pelo número de horas trabalhadas pelos indivíduos, orientando-nos pelo salário mínimo de $\mathrm{R} \$ 415,00$ em 2008.

As variáveis independentes são representativas da dinâmica do mercado de trabaIho, ou seja, variáveis associadas à definição salarial dos indivíduos como a posse ou não de carteira de trabalho assinada, sexo, escolaridade (entre 0 e 15 anos de estudo), idade e idade ao quadrado, para captar o declínio salarial na renda de indivíduos com idades avançadas. A variável raça, originalmente composta por cinco categorias, foi categorizada da seguinte maneira: os brancos continuaram com seu formato, ao passo que pardos e pretos foram agrupados por terem rendas médias estatisticamente iguais, e indígenas e amarelos foram excluídos devido ao baixo número de casos. 0 estudo utiliza simulações contrafactuais baseadas na comparação de

\section{Tabela 1 - Dados descritivos da subamostra das regiões metropolitanas, suas composições raciais e intrametropolitanas}

\begin{tabular}{l|c|c|c|c|c|c}
\hline $\begin{array}{c}\text { Regiões } \\
\text { Metropolitanas }\end{array}$ & $\begin{array}{c}\text { Número de } \\
\text { municípios }\end{array}$ & $\%$ Centro & $\%$ Brancos & $\begin{array}{c}\% \text { Brancos no } \\
\text { Centro }\end{array}$ & $\begin{array}{c}\text { \% Brancos na } \\
\text { periferia }\end{array}$ & $\begin{array}{c}\text { Número de } \\
\text { observações }\end{array}$ \\
\hline Recife & 13 & 41,4 & 38,6 & 41,9 & 36,3 & 4.051 \\
Salvador & 13 & 81,2 & 15,2 & 15,7 & 13,0 & 4.626 \\
Belo Horizonte & 34 & 46,7 & 38,8 & 42,6 & 35,5 & 4.106 \\
Rio de Janeiro & 18 & 51,9 & 51,4 & 56,2 & 46,2 & 4.877 \\
São Paulo & 39 & 57,2 & 58,2 & 60,9 & 54,5 & 6.617 \\
Porto Alegre & 31 & 32,3 & 80,1 & 79,1 & 80,5 & 5.803 \\
\hline
\end{tabular}

Fonte: PNAD (2008). Elaboração dos autores. 
valores preditos provenientes de três modelos de regressão de Mínimos Quadrados Ordinários (MQO) com a mesma especificação, mas baseados em amostras diferentes. 0 objetivo do uso dos três modelos é observar como o diferencial de rendimentos entre os grupos analisados se altera quando olhamos para 0 diferencial entre e intrarregiões metropolitanas brasileiras.

0 Modelo 1, que chamaremos de modelo Global, é composto pelas variáveis independentes descritas acima e por variáveis binárias indicadoras da cor da pele e para cada região metropolitana. Levamos em conta toda a amostra e permite comparar a renda média de brancos e negros, entre o núcleo e a periferia, e em cada metrópole. Essa é a forma de especificação geralmente utilizada na literatura sociológica para "levar em conta" os diferenciais regionais de renda (ex. Silva, 1999). Os resultados evidenciarão que esse modelo mascara desigualdades regionais por referir-se à média global das diferenças de rendimento entre grupos. 0 modelo é apresentado, entretanto, para fins didático-comparativos.

Para explorar mais a fundo o diferencial de rendimentos entre brancos e negros no núcleo e na periferia das regiões metropolitanas utilizamos modelos para amostras mais restritas. No Modelo 2, Metropolitano, são estimados coeficientes para cada região metropolitana. Assim, existe uma amostra para os indivíduos de cada região, visando captar a associação entre a renda e as covariáveis de interesse em cada uma delas. Nesse modelo são levadas em conta as especificidades e variações entre as regiões metropolitanas.

Por fim, utilizou-se no Modelo 3, Racial-Metropolitano, amostras específicas para cada grupo racial das regiões metropolitanas, resultando então, em doze subamostras. A proposta desse modelo é considerar ao máximo a especificidade dos grupos raciais, visando também comparar o diferencial intermetropolitano de rendimentos de negros e brancos no núcleo e na periferia.

Modelo 1

$$
\begin{gathered}
Y_{i}=\beta_{0}+\beta_{1}(\text { Idade })_{i}{ }_{i}+\beta_{3}(\text { CartAssin })_{i}+\beta_{4}(\text { sexo })_{i}+\beta_{5}(\text { escol_anos })_{i}+\beta_{6}(\text { raça })_{i} \\
+\beta_{7}(\text { nucleo })_{i}+\beta_{8}(\text { RMx })_{i}+\varepsilon
\end{gathered}
$$

Modelo 2

$$
\begin{aligned}
Y_{\text {iRM }(x)}=\beta_{0}+ & \beta_{1}\left(\text { Idade }^{2}{ }_{i}+\beta_{3}\left(\text { CartAssin }_{i}+\beta_{4}(\text { sexo })_{i}+\beta_{5}(\text { escol_anos })_{i}+\beta_{6}(\text { raça })_{i}\right.\right. \\
& +\beta_{7}(\text { nucleo })_{i}+\varepsilon
\end{aligned}
$$

Modelo 3

$$
\begin{aligned}
Y_{i j R M(x)}=\beta_{0}+ & \beta_{1}(\text { Idade })_{i}^{2}+\beta_{3}(\text { CartAssin })_{i}+\beta_{4}(\text { sexo })_{i}+\beta_{5}(\text { escol_anos })_{i} \\
& +\beta_{6}(\text { nucleo })_{i}+\varepsilon
\end{aligned}
$$


A comparação entre os três Modelos fornece uma dimensão metodológica atrelada à incerteza envolvida na escolha e na mensuração do diferencial de rendimentos racial e metropolitano. Ao compararmos os resultados dos três modelos evidenciamos a variabilidade do diferencial de rendimentos entre brancos e não brancos existente em diferentes níveis de agregação geográfica.

Para fins analíticos e comparativos, utilizamos os valores preditos dos salários de brancos e negros no núcleo e na periferia das regiões metropolitanas. Apresentamos os resultados comparando os salários preditos ao invés dos coeficientes, para facilitar a compreensão do que está sendo estudado. Os coeficientes de cada modelo se encontram no apêndice. Os salários preditos são calculados a partir de "tipos ideais" com as características mais prevalentes na amostra. Esse indivíduo típico é do sexo masculino, tem carteira assinada e idade e escolaridade médias, de forma que possamos isolar nossas variáveis-chave: núcleo e periferia.

\section{Resultados}

As perguntas que buscamos responder neste estudo se baseiam no diferencial de rendimentos entre brancos e negros, mas também em quanto esse varia entre e internamente às regiões metropolitanas. Consideramos importante a comparação entre as regiões metropolitanas, mas também dentro delas, tomando como preceito que as metrópoles são ocupadas desigualmente pelos grupos sociais.

Tabela 2 - Rendimento mensal médio observado nas regiões metropolitanas, em reais

\begin{tabular}{l|c|c|c|c}
\hline $\begin{array}{c}\text { Regiões } \\
\text { Metropolitanas }\end{array}$ & $\begin{array}{c}\text { Média salarial (R\$) } \\
\text { (Desvio-padrão) }\end{array}$ & Brancos (1) & Negros (2) & $\begin{array}{c}\text { Razão dos rendimentos } \\
(1) /(2)\end{array}$ \\
\hline Recife & $\begin{array}{c}729,12 \\
(1057,42)\end{array}$ & $\begin{array}{c}924,93 \\
(1298,53)\end{array}$ & $\begin{array}{c}605,85 \\
(849,56)\end{array}$ & 1,52 \\
\hline Salvador & $\begin{array}{c}807,26 \\
(1079,31)\end{array}$ & $\begin{array}{c}1468,24 \\
(1917,37)\end{array}$ & $\begin{array}{c}688,62 \\
(788,93)\end{array}$ & 2,13 \\
\hline Belo Horizonte & $\begin{array}{c}911,41 \\
(1141,01)\end{array}$ & $\begin{array}{c}1171,92 \\
(1476,15)\end{array}$ & $\begin{array}{c}746,27 \\
(698,81)\end{array}$ & 1,57 \\
\hline Rio de Janeiro & 1060,97 & $\begin{array}{c}1316,60 \\
(1706,16)\end{array}$ & $\begin{array}{c}790,79 \\
(790,30)\end{array}$ & 1,66 \\
\hline São Paulo & $(1366,80)$ & $\begin{array}{c}1384,30 \\
(1634,06)\end{array}$ & $\begin{array}{c}854,30 \\
(1994,47)\end{array}$ & 1,62 \\
\hline Porto Alegre & $\begin{array}{c}1162,67 \\
(1812,41)\end{array}$ & $\begin{array}{c}1086,55 \\
(1392,23)\end{array}$ & $\begin{array}{c}715,39 \\
(551,91)\end{array}$ & 1,51 \\
\hline Núcleo & $\begin{array}{c}1012,54 \\
(1278,46)\end{array}$ & $\begin{array}{c}1462,54 \\
(1871,99)\end{array}$ & $\begin{array}{c}778,92 \\
(1392,74)\end{array}$ & 1,88 \\
\hline Periferia & $\begin{array}{c}1101,00 \\
(1671,27)\end{array}$ & $\begin{array}{c}970,20 \\
(1127,73)\end{array}$ & $\begin{array}{c}678,43 \\
(586,16)\end{array}$ & 1,43 \\
\hline
\end{tabular}

Fonte: PNAD (2008). Elaboração dos autores. 
Observando dados descritivos sobre a renda dos indivíduos presentes na amostra em estudo, verificamos diferenças nos salários médios entre brancos e negros em cada região metropolitana, e entre os municípios centrais e periféricos. Observamos essas diferenças na Tabela 2.

A maior desigualdade salarial encontra-se em Salvador, onde o salário mensal médio dos brancos é $113 \%$ maior que o dos negros. Em Porto Alegre, esse diferencial é de $51 \%$. Como forma de fazer as comparações considerando as devidas heterogeneidades, os modelos de mínimos quadrados ordinários auxiliam na estimação dos salários dos grupos analisados. Esses são adequados para comparações mais fidedignas, controlando as rendas preditas pelas características que podem influenciar nos diferenciais.

Utilizando os valores preditos do Modelo 1, observa-se que a cor da pele e a inserção regional associam-se ao diferencial de rendimento. Na Tabela 2, o valor do rendimento mensal predito mantém pouca variação de uma região metropolitana para outra. Apesar da pouca variabilidade intermetropolitana do diferencial de rendimentos entre brancos e negros e entre núcleo e periferia, o modelo atesta a hierarquia centro/periferia e branco/negro.

A Figura 1 mostra que a disparidade dos rendimentos entre brancos e negros é equivalente nos núcleos e periferias metropolitanas,

Figura 1 - Razão entre os rendimentos preditos de brancos e negros, e entre os moradores do núcleo e da periferia das regiões metropolitanas (Modelo Global)

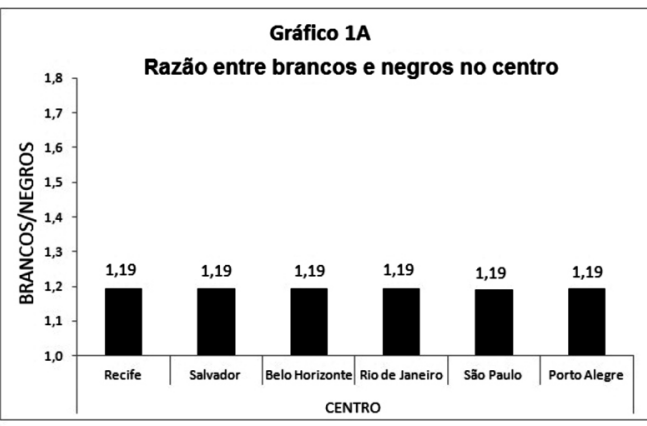

Gráfico 1C

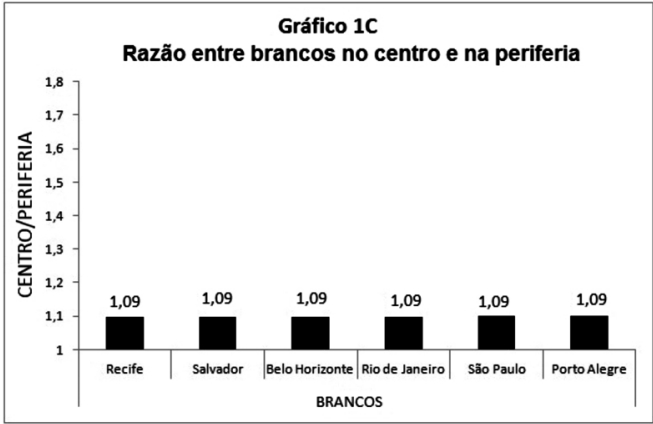

Gráfico 1B

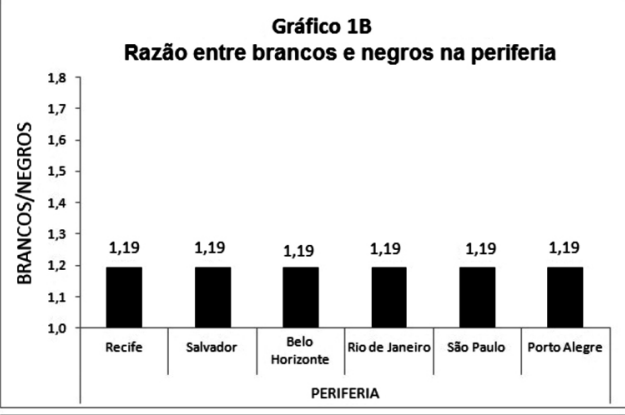

Gráfico 10

Razão entre negros no centro e na periferia

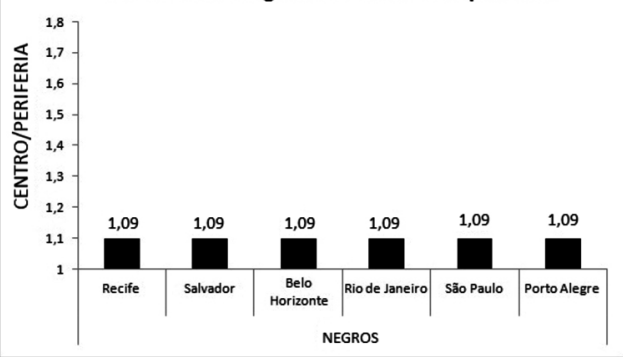

Fonte: PNAD (2008). Elaboração dos autores. 
ficando em torno de 19\% em todas as regiões metropolitanas. Se comparados à razão do diferencial devido ao "local de moradia", tanto brancos quanto negros em quaisquer núcleos metropolitanos ganham cerca de $10 \%$ a mais do que aqueles que residem nas periferias. Apesar do diferencial entre brancos e negros ser superior ao diferencial de rendimentos dos moradores do centro e da periferia, não há distinção no diferencial salarial racial entre as regiões. A inserção metropolitana pouco acrescenta na diferenciação entre elas. Os modelos seguintes, entretanto, alteram esses resultados.

0 teste de igualdade de coeficientes demonstrou que esses não eram iguais para as regiões metropolitanas, exceto para Belo Horizonte e Rio de Janeiro. 0 que ocorre, de fato, é que cada região tem um coeficiente, estatisticamente distinto, mas as razões são muito parecidas, diferenciando-se a partir da terceira casa decimal. Ou seja, o salário predito de um branco no centro recifense é de $\mathrm{R} \$ 820,94$ e de um negro, $\mathrm{R} \$ 688,05$. Em São Paulo, esses mesmos "tipos ideais" têm um salário predito de $R \$ 1.210,07$ e $R \$ 1.013,37$. Assim, apesar dos diferentes valores, a razão para ambas metrópoles é de 19\% $(1,19)$.

No modelo Metropolitano, as regiões metropolitanas já apresentam maiores variações nas razões dos rendimentos de brancos e negros, assim como nos locais de moradia. Apesar de mantido o "formato" da desigualdade, ou seja, quem ganha mais e quem ganha menos, a intensidade do diferencial se modifica abruptamente em comparação ao modelo anterior. A Figura 2 apresenta os

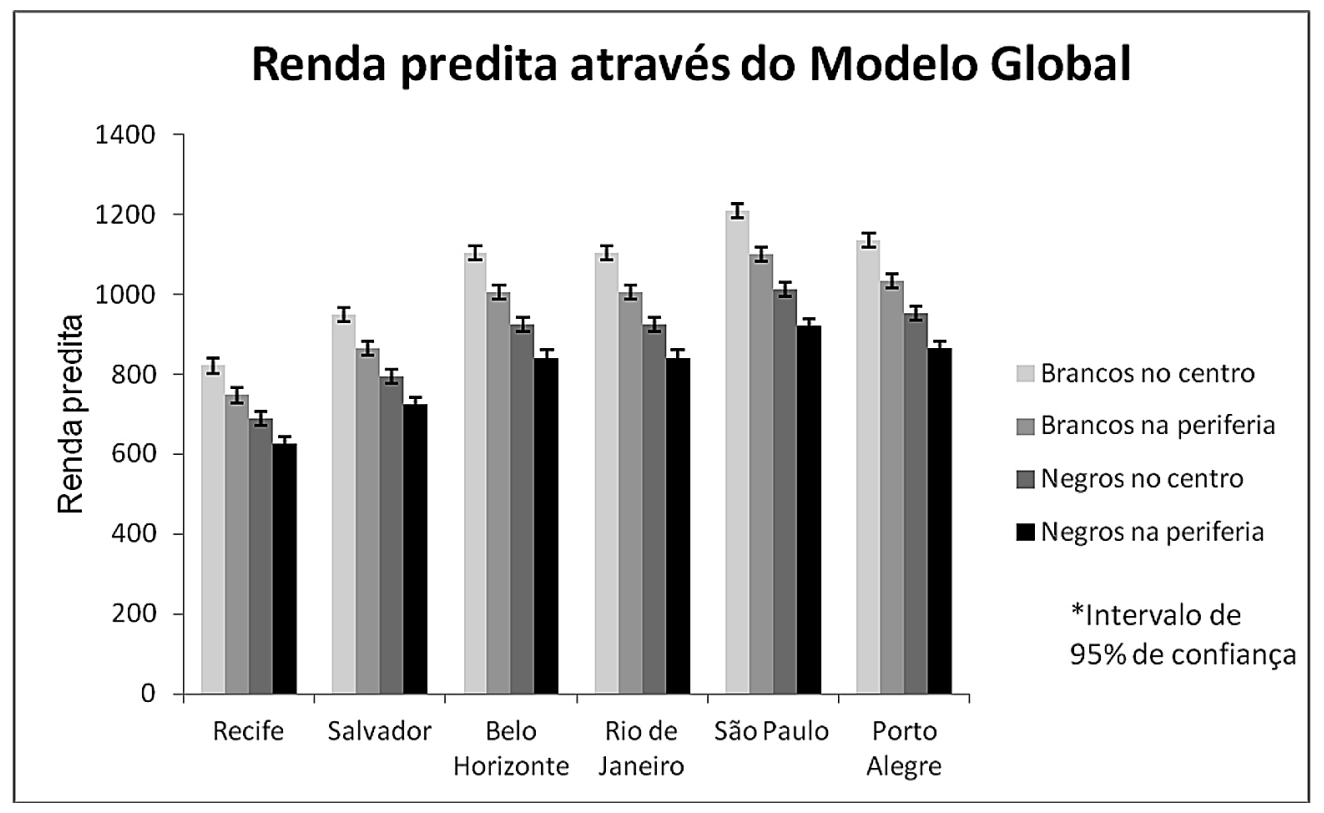


Figura 3 - Razão entre os rendimentos preditos de brancos e negros, e entre moradores do núcleo e da periferia das regiões metropolitanas

(Modelo Metropolitano)

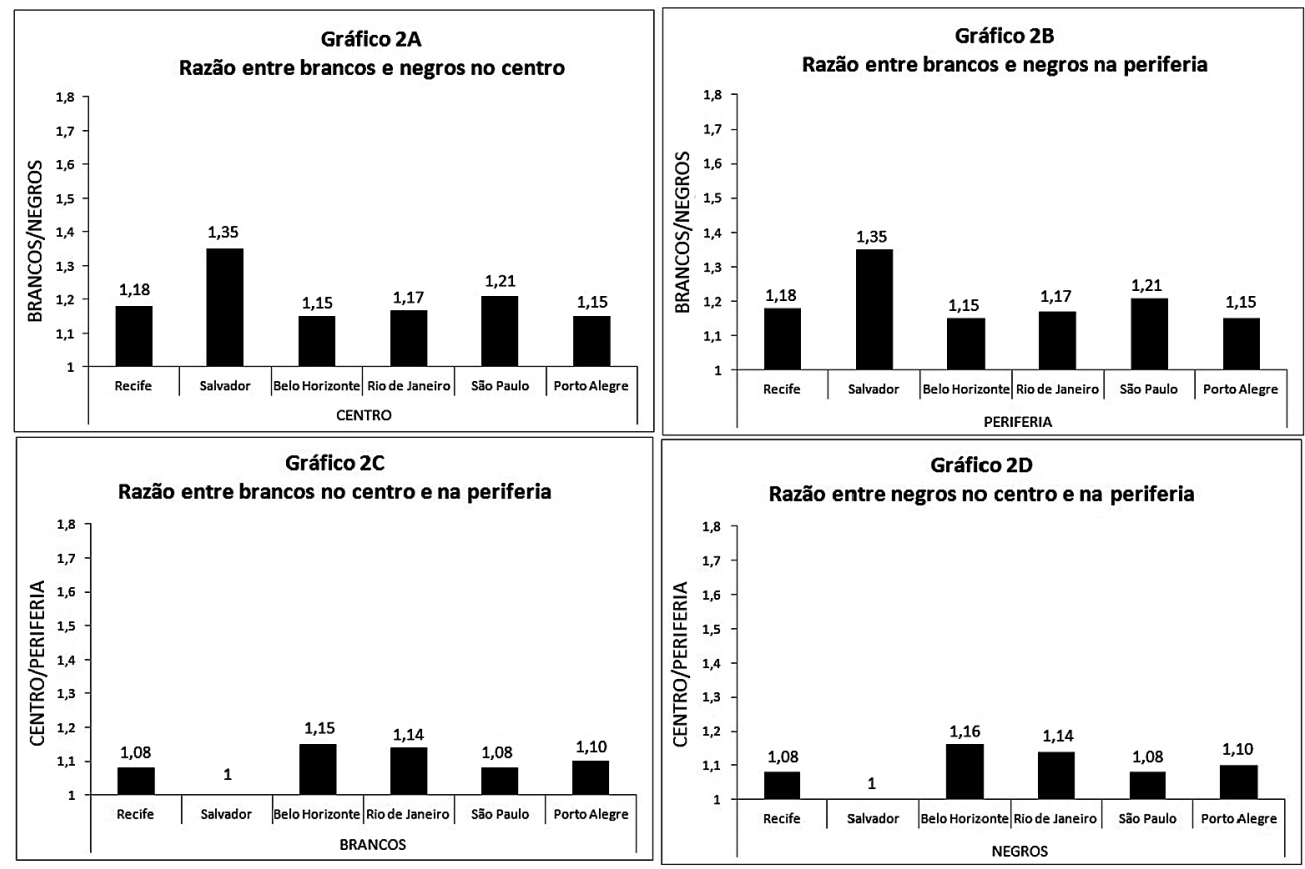

Fonte: PNAD (2008). Elaboração dos autores.

diferenciais de rendimento constatados entre os negros ou brancos que se encontram no núcleo ou na periferia quando o segundo modelo é utilizado.

0 modelo Racial-Metropolitano, quando comparado ao segundo modelo, também apresenta diferenciais maiores entre brancos e negros, quando esses estão em uma mesma região metropolitana. Essa variação de um modelo para outro é grande, se considerarmos que o diferencial dobrou ou mais que dobrou em muitos casos. Por exemplo, em São Paulo, o diferencial entre brancos e negros, no núcleo, que era de $21 \%$ no modelo Metropolitano, passa para $47 \%$ no Racial-Metropolitano.
Em Porto Alegre, o hiato racial na periferia passou de $15 \%$ para $39 \%$ dependendo do modelo utilizado.

Os três modelos apresentaram semeIhanças, quando observamos que a "ordem" do diferencial foi mantida, por exemplo, Salvador teve a maior razão branco/negro em todos eles, ou Belo Horizonte e Rio de Janeiro tiveram o maior diferencial núcleo/periferia. No Modelo Global, apesar das regiões metropolitanas não apresentarem diferenças significativas, em todas foram atestados um diferencial entre brancos e negros, e entre núcleo e periferia, com valores muito próximos à média dos demais modelos. Contudo, nesse primeiro 
Figura 4 - Razão entre os rendimentos preditos de brancos e negros, e moradores do núcleo e da periferia das regiões metropolitanas (Modelo Racial-Metropolitano)

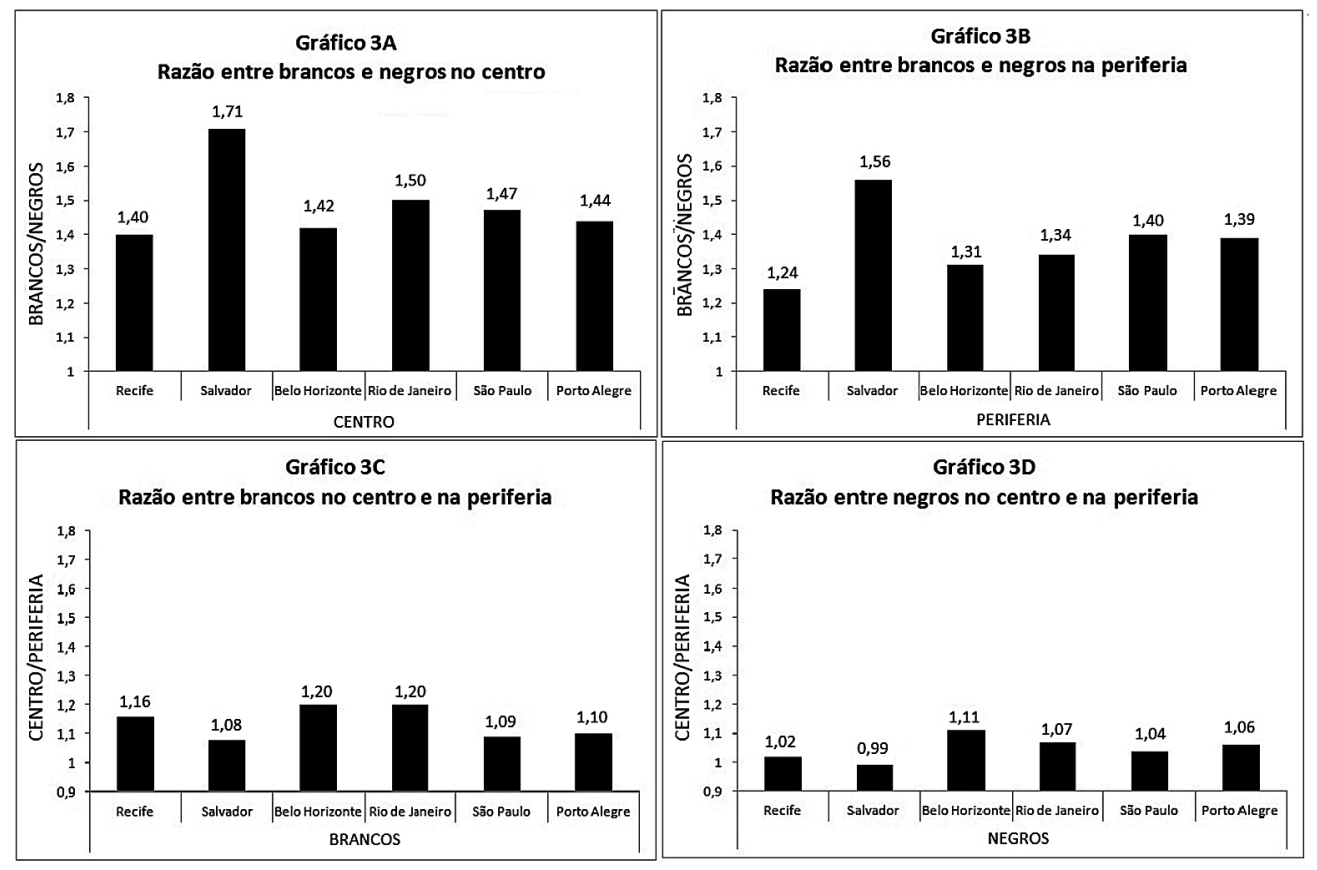

Fonte: PNAD (2008). Elaboração dos autores.

modelo não foi possível observar diferenças substantivas quando feita a análise intermetropolitana. 0 Modelo Metropolitano demonstrou variação intermetropolitana nas razões dos salários. A partir desse, ficaram explícitas tendências e diferenciações entre as cidades estudadas, por exemplo, quais tinham estruturas urbanas mais rígidas, ${ }^{6}$ em comparação a outras que tinham hierarquias por cor de pele mais fortes. Porém, nesse modelo as razões de diferencial entre brancos e negros encontradas no núcleo se repetiam na periferia, assim como o que acontecia nas razões de brancos no núcleo e brancos na periferia, ou para os negros. De fato, há diferenças na intensidade das razões encontradas entre eles, mas não nos caminhos e apontamentos de cada um deles. Eles não são contraditórios entre si, apenas expõem dados que são geograficamente mais enfáticos que outros. 
Os salários preditos apresentados para Salvador também tiveram mudanças consideráveis, apesar da variação segundo o local de residência permanecer muito baixo. Para os brancos localizados no centro, seus salários preditos são $8 \%$ maiores, enquanto para os negros não há diferença significativa. A variação conforme a cor da pele, por sua vez, foi incrementada de maneira substancial. Assim como no modelo anterior, Salvador permanece com a maior razão entre salários preditos de brancos e negros. Porém, o diferencial de 35\% favorável aos brancos no modelo anterior passa para $71 \%$ no centro e $56 \%$ nas periferias ao considerarmos o Modelo Racial-Metropolitano.

As regiões que apresentaram no Modelo Metropolitano uma estrutura socioespacial com maiores impactos nos rendimentos preditos, Rio de Janeiro e Belo Horizonte, mantêm essa posição no Modelo Racial-Metropolitano. No modelo anterior, porém, a renda predita calculada para os negros residentes do núcleo metropolitano era equivalente à de um branco na periferia, o que não ocorre no Modelo Racial-Metropolitano. Nesse, a associação estatística entre renda e cor da pele é superior àquela da variável núcleo-periferia, e os núcleos se mostram territórios mais diferenciadores do que as periferias, algo que não havia sido tão explicitado no segundo modelo.

\section{Discussão}

Atentando-nos às hipóteses elencadas, inferimos que o diferencial de rendimentos é favorável aos brancos e varia consideravelmente entre as regiões metropolitanas, o que não é novidade e já foi mostrado em trabalhos anteriores (Cavalieri e Fernandes, 1998; Lima, 1999). Os resultados do terceiro modelo, porém, demonstram outra faceta das dimensões metropolitanas e raciais: há variações intrametropolitanas na "intensidade" do diferencial entre brancos e negros.

Seguindo as perguntas que nortearam este estudo exploratório, verificamos que a relação entre os grupos raciais é mais desigual nos centros metropolitanos. Esses resultados foram invariáveis nas nossas subamostras. As periferias são predominantemente mais pobres e homogêneas que os núcleos, pelo menos racialmente. Brancos e negros nas periferias são socioeconomicamente mais parecidos que nos centros, se assemelhando em condições desfavoráveis, mas não na ascensão social.

Em consonância com a hipótese do spatial mismatch observamos que, de fato, os que residem em municípios periféricos apresentam considerável desvantagem de renda em relação aos que vivem no centro, ainda que na periferia as desigualdades raciais sejam menores. Os centros têm salários e composição racial branca acima da média. Estar na periferia, portanto, implica não só rendimentos inferiores aos dos brancos, mas também rendimentos absolutamente menores, configurando assim uma situação de dupla desvantagem para os que ali se encontram.

Comparando regiões metropolitanas, temos Recife e Salvador com situações opostas e extremas no que concerne à razão dos rendimentos raciais. Essas nos dão espaço para desbancar generalizações regionais, que comparam as macrorregiões, e também para refutar a hipótese de Fernandes (2008), segundo a qual as desigualdades raciais seriam superadas na 
medida em que o país se modernizasse a partir da industrialização e da racionalização crescente do mundo. Se a hipótese de Florestan e seus ex-alunos fosse irrefutável, não observaríamos o maior e o menor diferencial racial de renda em áreas do Nordeste, conhecidamente menos desenvolvidas economicamente.

Comparando entre metrópoles, reafirma-se a ideia de que uma composição racial majoritariamente negra não ameniza o diferencial, pois Salvador teve diferenciais favoráveis aos brancos maiores que Porto Alegre, por exemplo, onde a maioria é autodeclarada branca. No caso específico de Salvador, os resultados são coerentes com o clássico estudo de Pierson (1945), que mostra como os brancos soteropolitanos ocupam posições mais prestigiadas que os negros, independente de a maioria da população ser negra. Mesmo diante do histórico de militância do movimento negro em Salvador, não houve melhoria ou redução das desigualdades raciais. Entre o centro e a periferia de Salvador, não houve diferenças estatisticamente significativas nas desigualdades raciais observadas.

Qual seria a importância da cor da pele vis-à-vis à localização intrametropolitana? Os resultados obtidos demonstram que a cor da pele tem maior impacto no salário predito dos indivíduos do que a localização dentro da cidade. De fato, a razão do diferencial de renda é maior para brancos e negros do que para residentes no núcleo ou na periferia. Contudo, a variável núcleo/periferia é estatisticamente significante na maioria das regiões, de modo a não ser desprezada. Como chamam a atenção Campante et al. (2004), as análises nacionais ocultam uma série de variações regionais, que podem ter implicações para políticas públicas locais. Demonstramos que, de fato, há significância entre a diferenciação centro/periferia. A conclusão que se segue é que a intensidade da desigualdade que se deve a um ou outro fator (localização geográfica ou cor da pele) varia consideravelmente por região metropolitana.

Em Belo Horizonte e no Rio de Janeiro, o diferencial de rendimentos para brancos e negros no centro e na periferia são muito parecidos, pois os brancos ganham $15 \%$ a mais que os negros no núcleo e na periferia da capital mineira, e 17\% na capital fluminense. Porém, a peculiaridade dessas duas regiões se encontra quando comparamos as razões à de aspecto territorial. Nesse aspecto, essas duas cidades apresentam diferenciais médios de rendimentos entre centro e periferia maiores do que nas demais metrópoles. A literatura, inclusive, chama a atenção para a segregação nessas duas metrópoles, com centros elitizados e periferias pobres, o que é condizente com o que foi encontrado. ${ }^{7}$ Portanto, o diferencial de renda entre moradores do centro e da periferia, e para negros e brancos é muito parecido, ao contrário de outras regiões em que o diferencial por raça era visivelmente maior. Esse ponto é importante para mostrar que a desigualdade é distinta entre as regiões metropolitanas. Isso pode corroborar as ideias de alguns autores que mostram Belo Horizonte e Rio de Janeiro como metrópoles segregadas, com municípios do entorno mais pobres (Marques et al., 2008; Andrade e Mendonça, 2010). Em São Paulo, por exemplo, já se vê um espraiamento dos grupos, através dos condomínios fechados nas periferias, mesmo que não haja grande interação entre esses (Caldeira, 2003). 
Os resultados sugerem que fatores específicos (quiçá culturais) a cada região metropolitana contribuem para explicar a variabilidade existente entre elas, tanto no que concerne ao diferencial geral, quanto internamente entre centro e periferia. Entretanto, se as especificidades têm papel importante na explicação dos resultados de cada uma, ambas as divisões têm hierarquias demarcadas: brancos com melhores resultados que negros, assim como centro meIhor que periferia. Portanto, a separação entre centro e periferia é uma possibilidade explicativa da intensidade dos diferenciais.

\section{Considerações finais}

Os estudos sobre desigualdade racial, e mais especificamente sobre os diferenciais de rendimento, buscam trazer variáveis que explicam os ganhos médios dos grupos raciais. Em geral, o que essas variáveis não conseguem explicar é atribuído à discriminação na definição salarial. Contudo, admite-se também a existência de fatores não observados que podem influenciar os diferenciais. Nossos resultados elucidam que existem segmentações que aumentam ou diminuem o diferencial. Mostramos que a segmentação territorial é uma forma de interação com a variável racial. Isso tem implicações relevantes para as políticas públicas mitigadoras de desigualdades já que a segregação residencial está associada à qualificação (principalmente escolaridade) e à angariação de capital social (Flores, 2006; Andrade e Silveira, 2011).

Este trabalho utilizou-se de três modelos que possibilitaram fazer inferências teóricas e metodológicas. No aspecto metodológico, explicitamos como a escolha de modelos estatísticos pautados por distintos níveis de agregação geográfica amostral é capaz de ressaltar maiores intensidades das dinâmicas que se busca mensurar, mesmo quando a direção das associações constatadas em cada um deles é a mesma. Eles não apresentaram resultados contraditórios entre si, mas corroboraram a intensidade das diferenças médias entre os rendimentos dos grupos raciais investigados.

Nos aspectos teóricos, o trabalho apontou como os diferenciais raciais de rendimentos variam entre as regiões metropolitanas. A composição racial não se mostrou tão influente na variação dos diferenciais, tendo em vista que a ordem das regiões que têm mais brancos não é necessariamente aquela com maiores diferenciais. Outro resultado reafirmado pelos modelos é a "influência" da localização intrametropolitana na definição dos rendimentos preditos, tanto no que concerne a comparação entre indivíduos de mesma cor - brancos no núcleo ganham mais que brancos na periferia -, como entre indivíduo de cores diferentes - o núcleo se mostrou mais desigual em termos salariais do que a periferia.

Nossa conclusão, por um lado, corrobora um resultado prévio já bem estabelecido: características atribuídas, como a cor da pele, são fatores-chave na diferenciação salarial. Por outro lado, a estrutura socioespacial das cidades brasileiras compreende dinâmicas que Ihe são peculiares, nas quais há hierarquias definidas do centro para periferia, independente da composição racial local. Ou seja, em todas elas existem estruturas sociais e geográficas definidas, mas que também têm uma relação com fatores culturais. Como proposta 
exploratória, aprofundamos as possibilidades de uso da variável centro-periferia. Assim, estudos sobre relações raciais e políticas públicas que visem a mitigação das desigualdades devem voltar-se às especificidades inter e intrametropolitanas para atuarem de forma focada e eficiente, dando a devida atenção às desigualdades mais desiguais.

\section{Leonardo Souza Silveira}

Universidade Federal de Minas Gerais, Centro de Pesquisas Quantitativas em Ciências Sociais. Belo Horizonte/MG, Brasil.

Issilveira@ymail.com

\section{Jerônimo Oliveira Muniz}

Universidade Federal de Minas Gerais, Departamento de Sociologia, Centro de Pesquisas Quantitativas em Ciências Sociais. Belo Horizonte/MG, Brasil. jeronimo@fafich.ufmg.br

\section{Notas}

(1) Marques et al. (2008) utilizam do Índice de Status Socioeconômico Ocupacional (ISEI) para demonstrar como os grupos sócio-ocupacionais estão concentrados nos municípios das regiões metropolitanas do Rio de Janeiro e São Paulo de maneira "relativamente radial, concêntrica e segregada, embora com heterogeneidades localizadas significativas" (2008, p. 228).

(2) A heterogeneidade das redes sociais é reconhecida como um ativo dos indivíduos, já que eles podem ter maior variedade de informações a partir dessas, ao contrário de redes homogêneas, nas quais o fluxo de informações e influências tende a ser muito parecidos. Veja, por exemplo, a discussão sobre laços fracos apresentada por Granovetter (1973) .

(3) Os municípios-polo neste caso são: Recife, Salvador, Belo Horizonte, Rio de Janeiro, São Paulo e Porto Alegre.

(4) Nas pesquisas censitárias e amostrais, o IBGE se utiliza das categorias "preta" e "parda" para coletar a informação sobre raça. Porém, estudos revelam que ao analisar os rendimentos de pretos e pardos provenientes do mercado de trabalho, estes eram estatisticamente semelhantes, unindo as duas categorias em uma: negros ou não-brancos. Neste trabalho, com dados da PNAD (2008), os testes de médias indicaram que estas categorias possuem rendimentos estatisticamente iguais, e por isso, elas foram agrupadas. Para uma discussão mais profunda sobre o assunto, ver Silva (1999) e Muniz (2010). 
(5) Bailey e Telles (2006) também apontam que pode haver associação entre a composição racial e a propensão dos indivíduos se declararem em termos ambíguos - como moreno -, na sua autoclassificação. Já no estudo da segregação residencial, Telles (1992) não encontrou associação significativa da imigração europeia.

(6) "Estruturas urbanas mais rígidas" implicam maior diferenciação entre núcleo e periferia. Nas regiões metropolitanas de Belo Horizonte e do Rio de Janeiro, viver no núcleo metropolitano pode representar um rendimento mensal bem superior do que na periferia, ao passo que em outras essa diferenciação não é tão grande.

(7) Para Belo Horizonte, ver Guimarães (1991), Villaça (2001), Andrade (2009). Para o Rio de Janeiro, ver Marques et al. (2008).

\section{Referências}

ALBA, R. e LOGAN, J. (1993). Minority proximity to whites in suburbs: an individual-level analysis of segregation. American Journal of Sociology, v. 98, n. 6, pp. 1388-1427.

ALBA, R.; LOGAN, J. e STULTS, B. (2000). How segregated are middle-class African Americans? Social Problems, v. 47, n. 4, pp. 543-585.

ANDRADE, L. T. (org.) (2009). Como anda Belo Horizonte. Rio de Janeiro, Letra Capital/Observatório das Metrópoles.

ANDRADE, L. T. e MENDONÇA, J. G. (2010). Explorando as consequências da segregação metropolitana em dois contextos socioespaciais. Cadernos Metrópole, v. 12, n. 23, pp. 169-188.

ANDRADE, L. T. e SILVEIRA, L. S. (2011). Explorando o efeito-território. In: XIV ENCONTRO NACIONAL DA ANPUR. Anais. Rio de Janeiro.

ANDRADE, L. T. e JAYME, J. G. (2011). Centro e periferia: refletindo sobre seus significados no contexto das grandes cidades. In: IX REUNIÃO DE ANTROPOLOGIA DO MERCOSUL. Anais. Curitiba.

BAILEY, S. e TELLES, E. (2006). Multiracial versus collective Black categories: examining census classification debates in Brazil. Ethnicities, v. 6, n. 1, pp. 74-101.

BAILEY, S.; LOVEMAN, M. e MUNIZ, J. (2013). Measures of "race" and the analysis of racial inequality in Brazil. Social Sciences Review, v. 42, pp. 106-119.

BASTOS, J. e FAERSTEIN, E. (2012). Discriminação e saúde: perspectiva e métodos. Rio de Janeiro, Fiocruz.

BECKER, G. (1962). Investiment in human capital: a theoretical analysis. The Journal of Political Economy, v. 70, n. 5, Part 2, pp. 9-49.

BONDUKI, N. e ROLNIK, R. (1982). "Periferia da Grande São Paulo: reprodução do espaço como expediente de reprodução da força de trabalho". In: MARICATO, E. (org.). A produção capitalista da casa (e da cidade) do Brasil industrial. São Paulo, Alfa-Ômega. 
BOURDIEU, P. (1986). "The forms of Capital". In: RICHARDSON, J. (ed.). Handbook of theory and research for the sociology of education. Nova York, Greenwood.

CALDEIRA, T. (2003). Cidade de muros. São Paulo, Edusp/Editora 34.

CAMPANTE, F.; CRESPO, A. e LEITE, P. (2004). Desigualdade salarial entre raças no mercado de trabalho urbano brasileiro: aspectos regionais. RBE, v. 58, n. 2, pp. 185-210. Disponível em: http:// virtualbib.fgv.br/ojs/index.php/rbe/article/viewFile/874/562.

CAVALIERI, C. e FERNANDES, R. (1998). Diferenciais de salários por gênero e cor: uma comparação entre as regiões metropolitanas brasileiras. Revista de Economia Política, v. 18, n. 1 (69).

COSTA RIBEIRO, C. A. da (2006). Classe, raça e mobilidade social no Brasil. Dados - Revista de Ciências Sociais. Rio de Janeiro, v. 49, n . 4, pp. 833-873.

FERNANDES, F. (2008). A integração do negro na sociedade de classes. São Paulo, Globo.

FLORES, C. (2006). "Consequências da segregação residencial: teoria e métodos". In: CUNHA, J. M. P. da (org.). Novas metrópoles paulistas: população, vulnerabilidade e segregação. Campinas, Unicamp/Nepo.

FRANÇA, D. S. N. (2010). Raça, classe e segregação residencial no município de São Paulo. Dissertação de mestrado. São Paulo, Universidade de São Paulo.

FREYRE, G. (1987). Casa grande \& Senzala. Rio de Janeiro, J. Olympio.

GRANOVETTER, M. (1973). The strength of weak ties. The American Journal of Sociology, Chicago, v. 78, n. 6, pp. 1360-1380.

GUIMARÃES, B. M. (1991). Cafuás, barracos e barracões: Belo Horizonte, cidade planejada. Tese de Doutorado. Rio de Janeiro, Instituto Universitário de Pesquisas do Rio de Janeiro.

GUIMARÃES, N.; BRITO, M. e SILVA, P. (2010). O acesso a oportunidades de trabalho no Brasil: uma comparação intermetropolitana sobre os mecanismos de circulação da informação ocupacional e a reprodução da desigualdade. Texto para discussão 009/2010, São Paulo, Cebrap.

HASENBALG, C. (2005). Discriminação e desigualdades raciais no Brasil. Belo Horizonte, Ed. UFMG.

HASENBALG, C. e SILVA, N. (2003). Origens e destinos: desigualdades sociais ao longo da vida. Rio de Janeiro, luperj/Ucam/Topbooks/Faperj.

HASENBALG, C.; SILVA, N. e LIMA, M. (1999). Cor e estratificação social. Rio de Janeiro, Contra Capa Livraria.

HENRIQUES, R. (2001). Desigualdade racial no Brasil: evolução das condições de vida na década de 90. Texto para discussão - Ipea. Rio de Janeiro, Ipea.

IHLANFELDT, K. (1994). The spatial mismatch between jobs and residential locations within urban areas. Cityscape, Georgia State University.

KAIN, J. (1968). Housing segregation, negro employment and metropolitan decentralization. The Quartely Journal of Economics, n. 82, pp. 175-197.

(1992). The spatial mismatch hypothesis: three decades later. Housing Policy Debate. Universidade de Harvard, v. 3, n. 2, pp. 371-460. 
KAZTMAN, R. e FILGUEIRA, F. (2006). Las normas como bien público y como bien privado: reflexiones en las fronteras del enfoque AVEO. Montevideo, Universidad Católica del Uruguay, Serie Documentos de Trabajo del Ipes - Colección Aportes Conceptuales, n. 4.

LAGO, L. C. (2007). A "periferia" metropolitana como lugar do trabalho: da cidade-dormitório à cidade plena. Cadernos IPPUR. Rio de Janeiro, UFRJ, ago/dez.

LIMA, M. (1999). "Aspectos regionais do mercado de trabalho no Brasil”. In: HASENBALG, C.; SILVA, N. e LIMA, M. Cor e estratificação social. Rio de Janeiro, Contra Capa Livraria.

LIN, N. (1999). Social networks and status attainment. Annual Review Sociology. Palo Alto, v. 25, pp. 467-487.

LOVEMAN, M.; MUNIZ, J. O. e BAILEY, S. (2011). Brazil in Black and White? Race categories, the census, and the study of inequality. Ethnic and racial studies, pp. 1-18.

MARICATO, E. (1977). A proletarização do espaço sob a grande indústria. O caso de São Bernardo do Campo. Tese de doutorado. São Paulo, Universidade de São Paulo.

MARQUES, E. (2005). “Espaços e grupos sociais na virada do século XXI”. In: MARQUES, E. e TORRES, H. São Paulo: segregação, pobreza urbana e desigualdade social. São Paulo, Senac.

(2010). Redes sociais, segregação e pobreza. São Paulo, Editora Unesp/Centro de Estudos da Metrópole.

MARQUES, E.; SCALON, C. e OLIVEIRA, M. (2008). Comparando estruturas sociais no Rio de Janeiro e em São Paulo. Dados. Rio de Janeiro, v. 51, pp. 215-238.

MUNIZ, J. O. (2010). Sobre o uso da variável raça-cor em estudos quantitativos. Revista Sociologia e Política. Curitiba, v. 18, n. 36, pp. 277-291.

(2012). Preto no branco? Mensuração, relevância e concordância classificatória no país da incerteza racial. Dados. Rio de Janeiro, v. 55, pp. 251-282.

OSÓRIO, R. G. (2009). A desigualdade racial de renda no Brasil: 1976-2006. Tese de doutorado. Brasília, Universidade de Brasília.

PATILLO, M. (2005). Black-middle class neighborhoods. Annual Review of Sociology, n. 31, pp. 305-329.

PIERSON, D. (1945). Brancos e pretos na Bahia: estudo de contacto racial. São Paulo, Companhia Editora Nacional.

PIORE, M. (2008). "The dual labor market: theory and implications". In: GRUSKY, D. B. Social stratification: class, race and gender in sociological perspective. Colorado, Westview Press.

PNAD - Pesquisa Nacional por Amostra de Domicílios (2008). Microdados da PNAD 2008. Disponível em: www.ibge.gov.br.

RIBEIRO, L. C. Q., SILVA, E. T. e RODRIGUES, J. M. (2011). Metrópoles brasileiras: diversificação, concentração e dispersão. Revista Paranaense de Desenvolvimento. Curitiba, n. 120, pp. 171-201.

SANTOS, J. A. F. (2009). A interação estrutural entre a desigualdade de raça e de gênero no Brasil. Revista Brasileira de Ciências Sociais, v. 24, n. 70. 
SILVA, N. V. (1999). "Diferenciais raciais de rendimento". In: HASENBALG, C.; SILVA, N. e LIMA, M. Cor e estratificação social. Rio de Janeiro, Contra Capa Livraria.

SMALL, M. e NEWMAN, K. (2001). Urban poverty after 'The truly disadvantaged': the rediscovery of the family, the neighborhood, and culture. Annual Review Sociology, Palo Alto, v. 27, pp. 23-45.

SOARES, S. (2000). O perfil da discriminação no mercado de trabalho - Homens negros, mulheres brancas e mulheres negras. Texto para discussão n. 769. Brasília, IPEA.

(2008a). "A demografia da cor: a composição da população brasileira de 1890 a 2007". In: THEODORO, M. (org.). As políticas públicas e a desigualdade racial no Brasil - 120 anos após a abolição. Brasília, Ipea.

(2008b). "A trajetória da desigualdade: a evolução da renda relativa dos negros no Brasil". In: THEODORO, M. (org.). As políticas públicas e a desigualdade racial no Brasil - 120 anos após a abolição. Brasília, Ipea.

TELLES, E. (1992). Residential segregation by skin color in Brazil. American Sociological Review, v. 57, n. 2, pp. 186-197.

(2004). Race in another America. Princeton, Princeton University Press.

VILELA, E.; COLLARES, A. e NORONHA, C. (2012). A situação socioeconômica de minorias étnico/raciais no mercado de trabalho brasileiro. In: XXXVI ENCONTRO ANUAL DA ANPOCS. Anais. Águas de Lindóia/SP.

VILLAÇA, F. (2001). Espaço intra-urbano no Brasil. São Paulo, Studio Nobel/Fapesp.

WILSON, W. J. (1987). The truly disadvantaged: the inner city, the underclass, and public policy. Chicago: University of Chicago Press, 1990.

(2009). More than just race: being Black and poor in the inner city. Nova York, Norton \& Company.

Texto recebido em $11 /$ dez/2013

Texto aprovado em 4/fev/2014 
ANEXO

\section{Coeficientes do Modelo 1, de Mínimos Quadrados Ordinários (Global)}

\begin{tabular}{|c|c|c|c|}
\hline Log do salário por hora & Modelo restrito & Modelo Irrestrito & Coeficientes padronizados ${ }^{a}$ \\
\hline (Constante) & $\begin{array}{c}1,729^{*} \\
(0,0153)\end{array}$ & $\begin{array}{c}1,802^{*} \\
(0,0166)\end{array}$ & \\
\hline Idade & $\begin{array}{c}0,0211^{*} \\
(0,000392)\end{array}$ & $\begin{array}{c}0,0212^{*} \\
(0,000392)\end{array}$ & 0,3289549 \\
\hline Idade $^{2}$ & $\begin{array}{c}-0,000417^{*} \\
(3,03 e-05)\end{array}$ & $\begin{array}{c}-0,000452^{*} \\
(3,01 \mathrm{e}-05)\end{array}$ & $-0,091937$ \\
\hline Carteira assinada & $\begin{array}{c}0,148^{*} \\
(0,00950)\end{array}$ & $\begin{array}{c}0,135^{*} \\
(0,00941)\end{array}$ & 0,0829118 \\
\hline Homem & $\begin{array}{c}0,237^{\star} \\
(0,00801)\end{array}$ & $\begin{array}{c}0,241^{*} \\
(0,00791)\end{array}$ & 0,1618063 \\
\hline Anos de estudo & $\begin{array}{c}0,0958^{*} \\
(0,00135)\end{array}$ & $\begin{array}{c}0,0943^{*} \\
(0,00132)\end{array}$ & 0,4801315 \\
\hline Branco & $\begin{array}{c}0,216^{*} \\
(0,00778)\end{array}$ & $\begin{array}{c}0,177^{*} \\
(0,00826)\end{array}$ & 0,1197016 \\
\hline RM Salvador & & $\begin{array}{l}-0,244^{*} \\
(0,0119)\end{array}$ & $-0,088551$ \\
\hline RM Recife & & $\begin{array}{l}-0,389^{*} \\
(0,0120)\end{array}$ & $-0,1272354$ \\
\hline RM Belo Horizonte & & $\begin{array}{c}-0,0919 * \\
(0,0111)\end{array}$ & $-0,0395204$ \\
\hline RM Rio de Janeiro & & $\begin{array}{l}-0,0923^{*} \\
(0,0113)\end{array}$ & $-0,050905$ \\
\hline RM Porto Alegre & & $\begin{array}{c}-0,0639 * \\
(0,0104)\end{array}$ & $-0,0247199$ \\
\hline Intrametropolitano & & $\begin{array}{c}0,0959^{*} \\
(0,00801)\end{array}$ & 0,0646598 \\
\hline $\mathrm{N}$ & 30.080 & 30.080 & \\
\hline $\mathrm{R}^{2}$ ajustado & 0,368 & 0,391 & \\
\hline $\mathrm{BIC}$ & $-256637,496$ & $-257701,812$ & \\
\hline
\end{tabular}

Obs.: Erros-padrão apresentados dentro dos parênteses. Significância representada por:

${ }^{*} \mathrm{p}<0,01,{ }^{* *} \mathrm{p}<0,05,{ }^{* * *} \mathrm{p}<0,1$.

(a) Coeficientes padronizados são utilizados para que se possa fazer uma comparação entre quanto as covariáveis estão associadas com a variável dependente. Por exemplo, entre os coeficientes acima, a educação tem maior associação com a renda dos indivíduos. Seu coeficiente é dado por sua subtração da média da variável por seu desvio-padrão. Sua interpretação pode ser feita da seguinte maneira: o aumento de um desvio-padrão da variável X1 aumenta a variável dependente em um desvio-padrão. 


\section{Coeficientes do Modelo 2, de Mínimos Quadrados Ordinários (Metropolitano)}

\begin{tabular}{|c|c|c|c|c|c|c|}
\hline $\begin{array}{c}\text { Log do salário por } \\
\text { hora }\end{array}$ & $\begin{array}{c}\text { RM } \\
\text { Recife }\end{array}$ & $\begin{array}{c}\text { RM } \\
\text { Salvador }\end{array}$ & $\begin{array}{c}\text { RM } \\
\text { Belo Horizonte }\end{array}$ & $\begin{array}{c}\text { RM } \\
\text { Rio de Janeiro }\end{array}$ & $\begin{array}{c}\text { RM } \\
\text { São Paulo }\end{array}$ & $\begin{array}{c}\text { RM } \\
\text { Porto Alegre }\end{array}$ \\
\hline (Constante) & $\begin{array}{c}1.355^{*} \\
(0,0356)\end{array}$ & $\begin{array}{l}1.526^{*} \\
(0.0348)\end{array}$ & $\begin{array}{c}1.746^{*} \\
(0.0335)\end{array}$ & $\begin{array}{c}1.820^{*} \\
(0.0325)\end{array}$ & $\begin{array}{c}1.763^{*} \\
(0.0289)\end{array}$ & $\begin{array}{c}1.774^{*} \\
(0.0304)\end{array}$ \\
\hline Idade & $\begin{array}{c}0.0198^{*} \\
(0.00101)\end{array}$ & $\begin{array}{c}0.0214^{*} \\
(0.000905)\end{array}$ & $\begin{array}{c}0.0221 * \\
(0.000883)\end{array}$ & $\begin{array}{c}0.0187^{*} \\
(0.000877)\end{array}$ & $\begin{array}{c}0.0223^{*} \\
(0.000701)\end{array}$ & $\begin{array}{c}0.0205^{*} \\
(0.000703)\end{array}$ \\
\hline Idade $^{2}$ & $\begin{array}{c}-0.000158^{* * *} \\
(8.51 \mathrm{e}-05)\end{array}$ & $\begin{array}{l}-0.000219^{*} \\
(7.17 e-05)\end{array}$ & $\begin{array}{c}-0.000501 \text { * } \\
(6.63 e-05)\end{array}$ & $\begin{array}{c}-0.000406^{*} \\
(6.49 \mathrm{e}-05)\end{array}$ & $\begin{array}{c}-0.000508^{*} \\
(5.40 \mathrm{e}-05)\end{array}$ & $\begin{array}{l}-0.000469^{\star} \\
(5.45 e-05)\end{array}$ \\
\hline Carteira assinada & $\begin{array}{l}0.272^{*} \\
(0.0228)\end{array}$ & $\begin{array}{c}0.176^{\star} \\
(0.0205)\end{array}$ & $\begin{array}{c}0.0497^{* *} \\
(0.0213)\end{array}$ & $\begin{array}{l}0.0970 * \\
(0.0208)\end{array}$ & $\begin{array}{c}0.164^{*} \\
(0.0174)\end{array}$ & $\begin{array}{l}0.0640 * \\
(0.0177)\end{array}$ \\
\hline Sexo $($ Homem $=1)$ & $\begin{array}{c}0.157^{*} \\
(0.0202)\end{array}$ & $\begin{array}{c}0.256^{\star} \\
(0.0180)\end{array}$ & $\begin{array}{c}0.289^{*} \\
(0.0174)\end{array}$ & $\begin{array}{c}0.175^{*} \\
(0.0179)\end{array}$ & $\begin{array}{c}0.260 * \\
(0.0140)\end{array}$ & $\begin{array}{c}0.266^{*} \\
(0.0146)\end{array}$ \\
\hline Anos de estudo & $\begin{array}{c}0.0936^{*} \\
(0.00296)\end{array}$ & $\begin{array}{c}0.0973^{*} \\
(0.00301)\end{array}$ & $\begin{array}{c}0.0941^{*} \\
(0.00293)\end{array}$ & $\begin{array}{c}0.0879 * \\
(0.00276)\end{array}$ & $\begin{array}{c}0.0961^{*} \\
(0.00247)\end{array}$ & $\begin{array}{c}0.0975^{*} \\
(0.00256)\end{array}$ \\
\hline Raça $($ Branco=1) & $\begin{array}{c}0.165^{*} \\
(0.0203)\end{array}$ & $\begin{array}{c}0.303^{*} \\
(0.0283)\end{array}$ & $\begin{array}{c}0.138^{*} \\
(0.0182)\end{array}$ & $\begin{array}{c}0.160 * \\
(0.0178)\end{array}$ & $\begin{array}{c}0.190^{*} \\
(0.0137)\end{array}$ & $\begin{array}{c}0.145^{*} \\
(0.0166)\end{array}$ \\
\hline $\begin{array}{l}\text { Centro-Periferia } \\
(\text { Centro }=1)\end{array}$ & $\begin{array}{l}0.0818^{*} \\
(0.0198)\end{array}$ & $\begin{array}{l}0.00327 \\
(0.0214)\end{array}$ & $\begin{array}{c}0.146^{*} \\
(0.0174)\end{array}$ & $\begin{array}{c}0.134^{*} \\
(0.0175)\end{array}$ & $\begin{array}{l}0.0789 * \\
(0.0137)\end{array}$ & $\begin{array}{l}0.0968 * \\
(0.0165)\end{array}$ \\
\hline $\mathrm{N}$ & 4.051 & 4,626 & 4,106 & 4,877 & 6,617 & 5,803 \\
\hline $\mathrm{R}^{2}$ ajustado & 0,373 & 0.382 & 0.388 & 0.323 & 0.390 & 0.365 \\
\hline $\mathrm{BIC}$ & $-26066,763$ & $-30639,960$ & $-27393,085$ & $-32271,252$ & $-47043,367$ & $-40634,487$ \\
\hline
\end{tabular}

Obs.: Erros-padrão apresentados dentro dos parênteses. Significância representada por: ${ }^{*} p<0,01,{ }^{* *} p<0,05,{ }^{* * *} p<0,1$. 


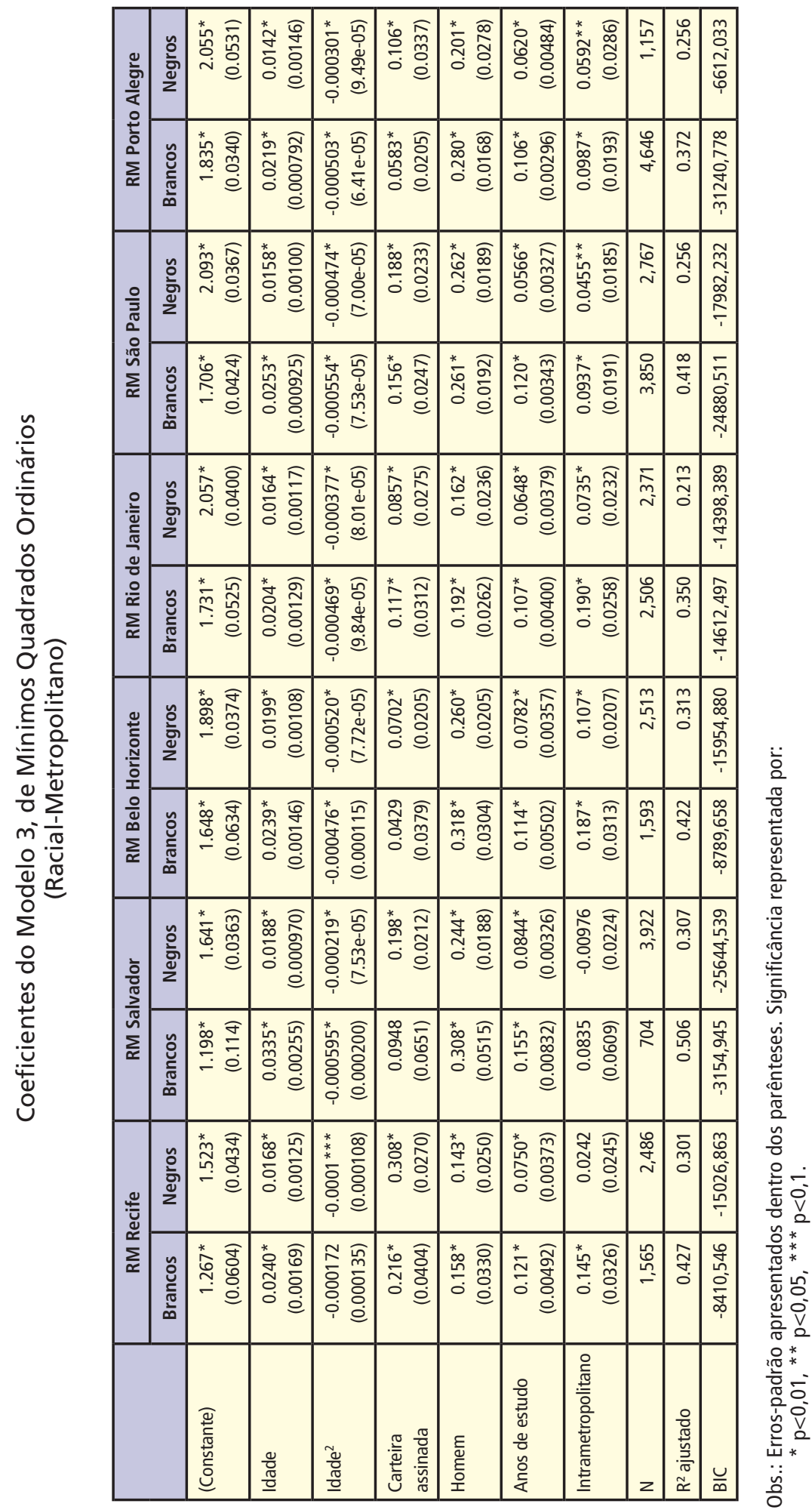


